\section{Hepatic microsomal enzyme induction: treatment of vitamin $D$ poisoning in a 7 month old baby}

Although it is well known that vitamin D should be used with care, cases of serious and sometimes lethal intoxication have been reported. ${ }^{12}$ Vitamin D can be stored in adipose tissue in large quantities, and its removal takes a long time. Iqbal and Taylor used induction of hepatic enzymes to treat a 77 year old woman intoxicated with vitamin D. ${ }^{34}$ We recently adopted this method to treat a baby who had received an overdose of vitamin $D$.

\section{Case report}

The patient, a boy, was born at term (birth weight $3800 \mathrm{~g}$, Apgar score 10); he was breast fed during the first two and a half months of life and received $400 \mathrm{U}$ cholecalciferol daily from the neonatal period. He remained in good general and nutritional health, but when he was 5 months old an "adequate" dose of cholecalciferol was prescribed. By mistake he was given $60000 \mathrm{U}$ daily for 50 days and then $120000 \mathrm{U}(3.0 \mathrm{mg})$ daily for 39 days. The treatment was stopped after he developed severe symptoms of intoxication, and he was admitted to hospital.

Examination and a history obtained from the mother showed him to have severe anorexia, constipation, and pallor; he was irritable or sleepy with conjunctivitis and moderate hepatomegaly. Urea, creatinine, and bilirubin concentrations and glutamic oxaloacetic transaminase and glutamic pyruvic transaminase activities were normal. Urinary and serum calcium concentrations were both $3.75 \mathrm{mmo} / 1$, serum phosphate concentration was $1.29 \mathrm{mmo} / 1$, and alkaline phosphatase activity was $94 \mathrm{U} / \mathrm{l}$. Vitamin D concentration, measured by high performance liquid chromatography, was $419 \mathrm{nmol} / \mathrm{l}$ and 25-hydroxyvitamin $D$ concentration, measured by a radiocompetitive test, $1025 \mathrm{nmol} / \mathrm{l}$.

All dairy products were immediately removed from the diet, and frusemide $1 \mathrm{mg} / \mathrm{kg}$ body weight/day was given for one week. Simultaneously phenytoin $5 \mathrm{mg} / \mathrm{kg} /$ day was given for 17 days and phenobarbitone $5 \mathrm{mg} / \mathrm{kg} /$ day for 133 days. Phenobarbitone was stopped for 14 days on the 44th day of treatment. After the first nine days of treatment there was a great improvement with serum and urine calcium concentrations becoming normal. When the phenobarbitone treatment was stopped the symptoms returned, but when it was restarted the child again improved. Treatment was stopped after 133 days.

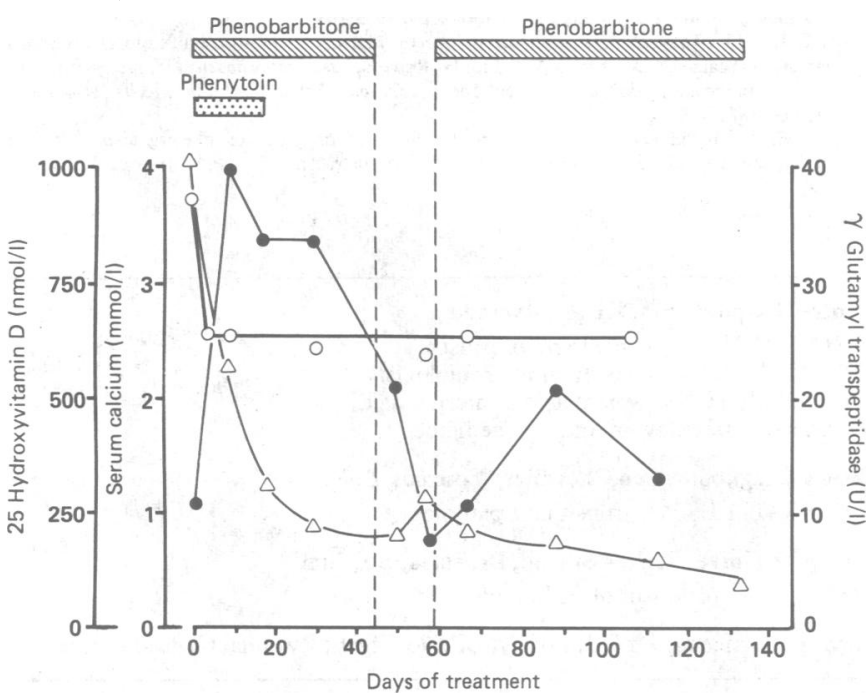

Serum calcium ( $\mathrm{O}-\mathrm{O}-$ ) and 25 -hydroxyvitamin $\mathrm{D}(\triangle-\Delta-)$ concentrations and $\gamma$ glutamyl transpeptidase activity (- - during treatment. Vertical broken lines indicate 14 days when treatment was stopped.

The figure shows serum calcium and 25-hydroxyvitamin D concentrations and $\gamma$ glutamyl transpeptidase activity (a measure of microsomal enzyme induction) during treatment. At the end of treatment the child's general condition was good, vitamin D concentration was moderately raised at $67 \cdot 1 \mathrm{nmol} /$, but 25 -hydroxyvitamin $\mathrm{D}$ concentration $(100 \mathrm{nmol} / \mathrm{l})$ was within the normal range; roughly three months later these concentrations were $53.6 \mathrm{nmol} / /$ and $122 \mathrm{nmol} /$, respectively.

\section{Comment}

To speed up the removal of vitamin D from this child we induced the hepatic microsomal enzymes by giving phenobarbitone and phenytoin.
These drugs are routinely used as anticonvulsants and are known to decrease vitamin $\mathrm{D}$ concentration and of ten lead to faulty bone mineralisation. Iqbal and Taylor used glutethimide for the same purpose. ${ }^{3}$ Our case shows that excess vitamin $D$ in a baby can be dealt with by hepatic enzyme induction. Treatment should be continued for at least three months and should be ended only when the 25 -hydroxyvitamin D concentration has dropped to within the range $100-150 \%$ of normal.

1 Paterson CR. Vitamin D poisoning: survey of causes in 21 patients with hypercalcaemia. Lancel 1980;i:1164-5.

2 Corvilain J, Fuss M, Karmali R, Gillet C. Effets toxiques de la vitamine D et ses metabolites Médecine et Hygiène 1984;42:2526-30.

3 Iqbal SJ, Taylor WH. Treatment of vitamin $D_{2}$ poisoning by induction of hepatic enzymes. BrMed f 1982;285:541-2.

4 Goldberg DM. The expanding role of microsomal enzyme induction and its implications in clinical chemistry. Clin Chem 1960;26:691-9.

5 Prószyńska K, Lukaszkiewicz J, Jarocewicz N, Lorenc RS. Rapid method for measuring physiological concentrations of 25-hydroxyvitamin D levels in blood serum. Clin Chim Acta 1985;153:85-92.

(Accepted 10 fuly 1987)

Department of Biochemistry and Experimental Medicine, Child Health Centre, Al Dzieci Polskich 20, 04-736 Warsaw, Poland

IACEK LUKASZKIEWICZ, PHD, head of laboratory

KRYSTYNA PRÓSZYŃSKA, PHD, assistant professor

ROMAN S LORENC, MD, PHD, professor of medicine and biochemistry, head of department

Medical Academy, Paediatric Institute, Clinic of Infants and Metabolic Diseases, ul Dziatdowska 1, Warsaw, Poland

HALINA LUDWICZAK, MD, PHD, assistant professor

Correspondence to: Dr Lorenc.

\section{Jazz ballet bottom}

Abscesses in the natal cleft region are usually associated with infection of a pre-existing sacrococcygeal pilonidal sinus. The patients affected are commonly young men, and typically there is appreciable local growth of hair. The abscesses in such cases usually are associated with a proved sinus or pit and usually contain hairs.

We report three cases of natal cleft abscesses in young women in which there was no evidence of a pilonidal aetiology. All the cases were strongly associated with local trauma caused by jazz ballet exercises.

\section{Patients, methods, and results}

During the six months from November 1986 to April 1987 three young women were referred to this hospital as emergencies with presumed pilonidal abscesses of the natal cleft. In all three cases the onset of symptoms was clearly related to a period of jazz ballet exercises.

In all three cases the patients had no relevant medical history, and the result of a random blood glucose test was normal. The abscesses were all drained under general anaesthesia, and none was found to contain hairs or have other evidence of a pilonidal origin. In all three cases Staphylococcus aureus was cultured from the pus. The wounds were dressed regularly with eusol and gauze, and two healed uneventfully. The third patient, however, promptly returned to her jazz ballet classes after her wound had healed and equally promptly returned three weeks after her first admission with a recurrence of her abscess. This was treated in a similar fashion, and again $S$ aureus was cultured from the pus. The wound healed uneventfully, and after advice to avoid those jazz ballet exercises that entail trauma to the sacrococcygeal region there was no further recurrence.

\section{Comment}

Jazz ballet is a fairly new form of recreation that includes various exercises to music, some of which require the participant to sit on the floor with most of the body weight supported by the sacrococcygeal region. Considerable frictional trauma to this part of the body may occur, and it is apparently common to experience transient soreness after a class (personal communication). In our patients this progressed to the formation of a subcutaneous abscess, presumably due to infection of a local haematoma.

The role of local trauma in the aetiology of true pilonidal disease of the natal cleft has been discussed extensively in medical reports ${ }^{1-3}$; indeed, this condition has been termed jeep disease from the association of trauma with the seat of a jeep. ${ }^{4}$ Several reports of series of pilonidal abscesses describe atypical cases in which hairs could not be found associated with the lesions, ${ }^{12}$ and we believe that our cases show that local trauma can produce abscesses in 